\title{
Bio/processes for Sustainable Environment and Clean Energy
}

\author{
Achlesh Daverey ${ }^{1} \cdot$ Kasturi Dutta $^{2} \cdot$ Angana Sarkar $^{2}$ \\ Published online: 14 July 2021 \\ (C) The Author(s), under exclusive licence to Springer-Verlag GmbH Germany, part of Springer Nature 2021
}

The 2nd International Conference on Bioprocess for Sustainable Environment \&Energy (ICBSEE-2020) was held on 5-7th March 2020 at the National Institute of Technology Rourkela, India. It is the second conference in the "International Conference on Bioprocess for Sustainable Environment \&Energy (ICBSEE)" series. The first conference was held in 2018 (Dutta et al. 2020) and the third conference will be held in 2022 .

The ICBSEE-2020 was held in a hybrid mode due to COVID-19 travel restrictions. A total of 09 keynote lectures, 48 oral presentations, and 82 poster presentations were presented at the conference. We sincerely thank the keynote speakers Prof. Jih-Gaw Lin (National Chiao Tung University, Taiwan), Prof. Ji-Dong Gu (Guangdong Technion Israel Institute of Technology, China), Prof. Jega V. Jegatheesan (RMIT University, Australia), Prof. Rintu Banerjee (IIT Kharagpur, India), Prof. Sanjoy Ghosh (IIT Roorkee, India), Prof. Ramkrishna Sen (IIT Kharagpur), Prof. T. V. Ramachandra (IISC Bangalore, India), Prof. A. K Golder (IIT Guwahati, India), and Prof. Kusum Arunachalam (Doon University, India).

Environmental pollution (water, air, and soil) due to anthropogenic activities is a worldwide growing concern. Therefore, there is an urgent need to protect the environment from further deterioration through sustainable technologies and processes. It is also equally important to clean or remediate the already polluted sites through sustainable approaches. Bioprocesses have shown tremendous potential to achieve a sustainable environment through the production of green

Responsible Editor: Philippe Garrigues

Achlesh Daverey

ach15may@gmail.com; achlesh.senr@doonuniversity.ac.in

1 School of Environment and Natural Resources, Doon University, Dehradun, Uttarakhand 248012, India

2 Department of Biotechnology and Medical Engineering, National Institute of Technology, Rourkela, Odisha 769008, India energy, production of value-added products from waste materials, and also cleaning the environment via bioremediation and phytoremediation. Therefore, this special issue aimed to highlight the recent developments in bio/process approaches to achieve a sustainable environment, clean and green energy, and circular bio-economy.

This special issue "Bio/processes for Sustainable Environment and Clean Energy" of Environmental Science and Pollution Research (ESPR) contains 09 papers (03 review articles and 06 research articles) presented in ICBSEE-2020. These papers are selected based on a rigorous peer-review process by at least two reviewers. The rejection rate for this special issue was around $70 \%$. The review papers selected in this special issue highlight (1) the role of laccase enzyme in achieving clean energy, (2) simultaneous resource recovery and wastewater treatment by microalgae, and (3) the potential of microbes in enhanced oil recovery. The selected original research papers dealt with (1) phytoremediation of metal contaminated sites, (2) adsorption of toxic metals and (3) surfactants from the aqueous environment by using bioadsorbents, (4) bioconversion of waste shrimp and crab cell powder to bioactive metabolites, (5) energy-efficient conversion of agro-wastes into fermentable sugars by hybrid electromagnetic radiations, and (6) thermochemical extraction of reducing sugars from marine macroalgal biomass.

The Guest Editors would like to thank the Advisory and Steering Committee members of the conference for their support and valuable suggestions and advice, student volunteers for their support in coordinating the conference, and all the conference participants for their scientific contribution and making the ICBSEE-2020 a successful scientific event.

We sincerely thank Prof. Philippe Garrigues, Editor-inChief, ESPR, and Prof. Angeles Blanco, Editor, ESPR, for their support and guidance in setting up this special issue. We also thank ESPR Editorial Assistants, Florence Delavaud, Fanny Creusot, and Carmina Joy Cayago for their constant support and assistance. Guest Editors are also grateful to the Editors, who handled the peer-reviewed process of the submitted manuscript, and the anonymous reviewers, who 
devoted their valuable time, critically evaluated and provided constructive suggestions to improve the overall quality of the manuscripts submitted to this special issue.

Authors' contribution AD: writing - original draft, review, and editing. KD: writing - review and editing, project administration, and funding acquisition. AS: writing - review and editing, project administration, and funding acquisition.

Funding This conference was financially supported by Science \&Engineering Research Board (SERB), India via sanction order no SSY/2019/001515SERB. The conference was also supported by Microexpress Pvt. Ltd. and Eppendorf Pvt. Ltd.

\section{Declarations}

Competing interests The authors declare no competing interests.

\section{Reference}

Dutta K, Sarkar A, Kumar AK, Daverey A (2020) Preface to the first International Conference on Bioprocess for Sustainable Environment and Energy (ICBSEE-2018). Biocatal Agric Biotechnol 23:101465. https://doi.org/10.1016/j.bcab.2019.101465

Publisher's note Springer Nature remains neutral with regard to jurisdictional claims in published maps and institutional affiliations.

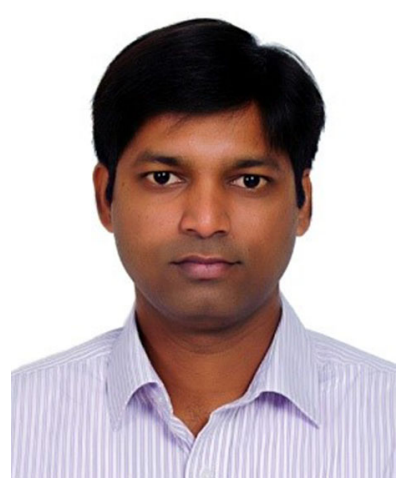

Dr. Achlesh Daverey (ORCID: 0000-0003-4480-0141) is an Assistant Professor in the School of Environment and Natural Resources at Doon University, Dehradun, Uttarakhand, India. $\mathrm{He}$ did his Ph.D. in Biotechnology from Indian Institute of Technology Guwahati (IIT Guwahati), India, in 2011. He has worked as a post-doctoral researcher in Institute of Environmental Engineering at National Chiao Tung University, Taiwan, before joining Doon University. His area of research includes biological wastewater treatment, phytoremediation of contaminated soil and water, utilization of wastes for value-added production, and bioprocess design and optimization. He is serving as an Editorial Board Member of "International Biodeterioration and Biodegradation" (Elsevier) and "SN Applied Sciences" (Springer) Journals. He has served as guest editor for various journals such as International Biodeterioration and Biodegradation (Elsevier); Biocatalysts and Agriculture Biotechnology (Elsevier); Sustainability (MDPI); Ecotoxicology (Springer), SN Applied Sciences (Springer); and Environmental Quality Management (Wiley). Dr. Daverey has published more than 40 research papers in $\mathrm{SCI} / \mathrm{SCOPUS}$ indexed journals and contributed 10 chapters in edited books.

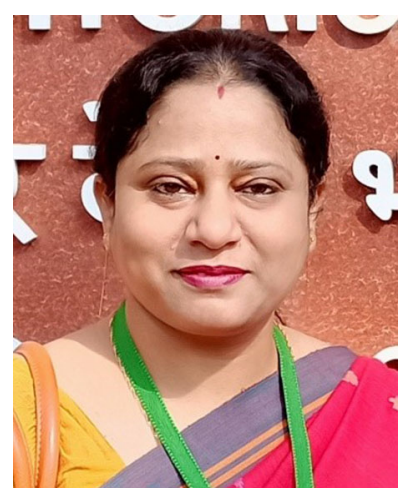

Dr. Kasturi Dutta is an Assistant Professor in the Department of Biotechnology and Medical Engineering, National Institute of Technology Rourkela, India. Dr. Dutta received her Ph.D. degree in Biotechnology from Indian Institute of Technology Guwahati, India, in 2012. She had worked as a postdoctoral researcher at National Chiao Tung University, Taiwan. She is currently working on the production of industrial and therapeutic enzymes from low-cost industrial wastes or by-products, and the production of biodiesel from microbial lipids by utilizing wastes and wastewater. Dr. Dutta has published $>25$ research papers and book chapters in peer-reviewed international journals (SCI/SCOPUS indexed) and edited books. She has served as guest editor for various journals such as International Biodeterioration and Biodegradation (Elsevier); Biocatalysts and Agriculture Biotechnology (Elsevier); Ecotoxicology (Springer), SN Applied Sciences (Springer); and Environmental Quality Management (Wiley).

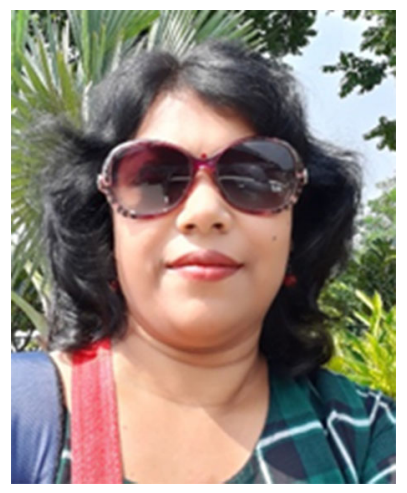

Prof. Angana Sarkar pursued her graduation in Agricultural Engineering from Bidhan Chandra Krishi Viswasvidyalaya, West Bengal, India, followed by post-graduation in Biotechnology \&Biochemical Engineering from Indian Institute of Technology, Kharagpur, India 2008. Later, she completed her Ph.D. in Environmental Biotechnology from Indian Institute of Technology, Kharagpur, India. Subsequently, she joined National Institute of Technology, Rourkela, India, in the year 2015 as an Assistant Professor in the Department of Biotechnology \&Medical Engineering. Her research area is mainly focused on (i) Pollutant detection using biosensors, (ii) groundwater bioremediation, (iii) wastewater (domestic and industrial) treatment, (iv) solid waste management by bio-refinery approach to produce environmental waste to value like bioethanol, pigment, and biofertilizers, and (v) hydrocarbon and other organic pollutants degradation. She is supervising several doctoral dissertations, master thesis, and advised many undergraduate students. She has a combined publication of $>60$ in various SCI cited journals of high repute, book chapters, and peerreviewed conferences. She is also serving as a reviewer in various journals of national and international repute. She has worked as handling editor in International Biodeterioration and Biodegradation (ELSEVIER) and Biocatalysts and Agriculture Biotechnology (Elsevier); Ecotoxicology (Springer), SN Applied Sciences (Springer); and Environmental Quality Management (Wiley), for special issue for International Conference on Bioprocess for Sustainable Environment and Energy (ICBSEE_2018 \&2020). 